Article

\title{
The Effect of Solution Treatment on the Si Particles' Morphology Evolution and the Thermal Conductivity and Tensile Properties of Sb-Modified Al-8Si-0.6Mg Alloys
}

\author{
Xiaopeng Liang ${ }^{1,2,3}$, Yihao Wang ${ }^{1}$, Li Wang ${ }^{2, *}$, Xinming Guo ${ }^{1}$, Liangjie Zhang ${ }^{1}$ and Huizhong Li $^{1,2,3, *}$ \\ 1 School of Materials Science and Engineering, Central South University, Changsha 410083, China; \\ liangxp@csu.edu.cn (X.L.); 193112130@csu.edu.cn (Y.W.); 193112088@csu.edu.cn (X.G.); \\ 213111069@csu.edu.cn (L.Z.) \\ 2 State Key Laboratory of Powder Metallurgy, Central South University, Changsha 410083, China \\ 3 Key Laboratory of Nonferrous Metal Materials Science and Engineering, Ministry of Education, \\ Central South University, Changsha 410083, China \\ * Correspondence: li.wang@csu.edu.cn (L.W.); lhz606@csu.edu.cn (H.L.)
}

check for updates

Citation: Liang, X.; Wang, Y.; Wang, L.; Guo, X.; Zhang, L.; Li, H. The Effect of Solution Treatment on the Si Particles' Morphology Evolution and the Thermal Conductivity and

Tensile Properties of Sb-Modified Al-8Si-0.6Mg Alloys. Metals 2022, 12, 377. https://doi.org/10.3390/ met12030377

Academic Editor: Renguo Guan

Received: 6 January 2022

Accepted: 10 February 2022

Published: 22 February 2022

Publisher's Note: MDPI stays neutral with regard to jurisdictional claims in published maps and institutional affiliations.

Copyright: (c) 2022 by the authors. Licensee MDPI, Basel, Switzerland. This article is an open access article distributed under the terms and conditions of the Creative Commons Attribution (CC BY) license (https:// creativecommons.org/licenses/by/ $4.0 /)$.

\begin{abstract}
The effects of solution treatment time on the morphology evolution of Si particles and the thermal conductivity and tensile properties of Sb-modified alloys were studied. The results show that the evolution of Si particles follows four mechanisms: spheroidization, necking and splitting of particles with large aspect ratios, fusion of spherical particles, and coarsening controlled by diffusion. The first three mechanisms mainly occur at the early stage of solution treatment. The addition of $\mathrm{Sb}$ does not change the evolution law of the Si particles, but it does change the contribution of various evolution mechanisms, including promoting spheroidization, fusion, and coalescence, as well as significantly reducing the coarsening rate, which makes the thermal modification of Sb-modified alloys more effective. The increase in thermal conductivity during solution treatment is related to the decrease of the anharmonicity of lattice vibration, lattice wave scattering, and electron scattering of Si particles. The $0.4 \mathrm{wt}$. \% Sb-modified alloy exhibits excellent tensile strength and elongation under as-cast T4- and T6-heat-treated conditions, because the modification significantly reduces the stress concentration of the Si particles and delays the germination and propagation of microcracks.
\end{abstract}

Keywords: Al-Si-Mg alloy; Sb element; solution treatment; thermal conductivity; tensile properties

\section{Introduction}

Hypoeutectic Al-Si alloys are widely used in modern industrial fields due to their good casting properties, excellent wear resistance, and low density. The development of communication technology also puts forward new requirements for casting aluminum alloys used in base-station structural parts, including excellent thermal conductivity and mechanical properties [1]. Since the thermal conductivity and mechanical properties of hypoeutectic Al-Si alloys are mainly determined by the morphology of their Si particles [2,3], in recent years, researchers have used chemical modification, melt superheating treatment, semi-solid casting, and other techniques to modify the morphology of Si particles [4-6].

Chemical modification, as the most common means of modification, has been paid more and more attention and research. Various elements (such as $\mathrm{Na}, \mathrm{Sr}, \mathrm{La}, \mathrm{Ce}, \mathrm{Sb}$, etc.) have been proven to be able to modify the morphology of Si particles [7-9]. In particular, the addition of $\mathrm{Sr}$ shows a significant effect on the modification of the Al-Si alloy but leads to an increase in the porosity of the ingot [10]. The modification effect of rare earth elements depends on the solidification rate, so it is difficult to obtain an ideal spheroidizing effect under the conventional cooling rate [11,12]. In addition, some modifiers exhibit high solid solubility in the matrix, which increases the lattice distortion of the matrix. Therefore, it is challenging to obtain high thermal conductivity and low porosity as-cast Al-Si alloys under conventional casting conditions. 
In addition to chemical modification, thermal modification has also been extensively studied in Al-Si alloys [13,14]. M. H. Abdelaziz et al. [15] studied the effect of long-term thermal modification on the evolution of Si particles in non-modified and Sr-modified 354 and 356 alloys and found that thermal modification of Si particles was more effective in Sr-modified alloys than in other, Sr-free alloys. In addition, the coarsening controlled by particle coalescence and Ostwald ripening mechanisms is the main evolution law of $\mathrm{Si}$ particles. However, they did not discuss the evolution of Si particles at the early stage of solution treatment. C. Lee et al. [16] found that thermal modification can make Si particles spheroidize and result in the edges becoming round, which plays an important role in avoiding the stress concentration of Si particles, germination of microcracks, and improving elongation after fracture; W. R. Osorio's research reached the opposite conclusion [17]. K. Li et al. [1] and M. H. Mulazimoglu et al. [18] analyzed the influence of thermal modification on the directional motion of electrons and both concluded that the splitting and spheroidization of particles caused by thermal modification reduced the obstacle to the motion of electrons and thus significantly improved the electrical conductivity of materials.

As a common modified element in Al-Si alloys, $\mathrm{Sb}$ can induce the formation of twins in Si and restrict the growth of Si particles [19]. Moreover, the solid solubility of Sb in the $\mathrm{Al}$ matrix is extremely low at room temperature, which avoids the adverse effect of element addition on the conductivity of the matrix [20]. However, the Si particles modified by $\mathrm{Sb}$ are still in strip shape, and their narrow morphology and sharp edges will split the matrix, which limits the improvement of electrical conductivity and mechanical performance that $\mathrm{Sb}$ can provide. In this work, chemical modification (Sb-modified) and thermal modification (solution treatment) were carried out simultaneously on an Al-8Si$0.6 \mathrm{Mg}$ alloy. The evolution law of Si particles and the contribution of various evolution mechanisms on the tensile properties and thermal conductivity were discussed, relative to the microstructure analysis of Si particles and the calculation of the scattering ability of the particle morphology of the electrons.

\section{Material and Experimental Details}

\subsection{Materials}

The investigated Al-8Si-0.6Mg alloys modified by Sb were prepared by using commercial pure Al (99.97 wt. \%), commercial pure Mg (99.97 wt. \%), Al-20 wt. \% Si, Al-10 wt. \% $\mathrm{Sb}$, and Al-50 wt. \% Cu master alloys. The alloys were melted in a graphite crucible using a resistance furnace in atmospheric environment. At first, the Al-Si master alloy and pure $\mathrm{Al}$ were melted together at $780{ }^{\circ} \mathrm{C}$. After the alloy was completely melted, pure $\mathrm{Mg}, \mathrm{Al}-\mathrm{Cu}$, and $\mathrm{Al}-\mathrm{Sb}$ master alloys were added and heated for $10 \mathrm{~min}$. Then, the melt was degassed by $\mathrm{C}_{2} \mathrm{Cl}_{6}$, and the temperature was decreased to $750{ }^{\circ} \mathrm{C}$. Finally, the melt was poured into a steel mold preheated to $200{ }^{\circ} \mathrm{C}$. The ingot size was $30 \mathrm{~mm} \times 40 \mathrm{~mm} \times 100 \mathrm{~mm}$, and the chemical compositions measured by Inductively Coupled Plasma-Atomic Emission Spectrometry (ICP-AES, PerkinElmer, MA, USA) are shown in Table 1.

Table 1. Chemical compositions of the experimental alloys (wt. \%).

\begin{tabular}{cccccccc}
\hline Code & Alloy & Si & $\mathbf{M g}$ & $\mathbf{S b}$ & $\mathbf{C u}$ & Fe & Al \\
\hline Alloy-1 & Al-8Si-0.6Mg-0Sb & 7.90 & 0.65 & 0 & 0.12 & 0.18 & Bal. \\
Alloy-2 & Al-8Si-0.6Mg-0.2Sb & 7.92 & 0.63 & 0.18 & 0.10 & 0.22 & Bal. \\
Alloy-3 & Al-8Si-0.6Mg-0.4Sb & 7.86 & 0.64 & 0.41 & 0.11 & 0.21 & Bal. \\
Alloy-4 & Al-8Si-0.6Mg-0.6Sb & 7.89 & 0.60 & 0.54 & 0.10 & 0.19 & Bal. \\
\hline
\end{tabular}

\subsection{Microstructure Characterization and Test Methods}

Samples with a size of $10 \mathrm{~mm} \times 10 \mathrm{~mm} \times 2 \mathrm{~mm}$ were cut from the middle position, $20 \mathrm{~mm}$ from the bottom of the ingots. After solution treatment at $540{ }^{\circ} \mathrm{C}$ for different periods of time, the samples were observed using an optical microscope (OM, 4XC-II, Shanghai Optical Instrument, Shanghai, China) after grinding and polishing. Then, these samples were deeply etched by mixed acid $\left(2.5 \mathrm{vol} \% \mathrm{HNO}_{3}, 2.5 \mathrm{vol} \% \mathrm{HF}\right.$, and $95 \mathrm{vol} \%$ 
$\mathrm{H}_{2} \mathrm{O}$ ) for $5 \mathrm{~min}$, and the morphology of the Si particles was observed using a field emission scanning electron microscope (FESEM, Sirion 200, Eindhoven, The Netherlands). A tensile test was carried out on an MTS-810 testing machine at room temperature. Three specimens for each alloy were tested. The gauge length of the specimen was $30 \mathrm{~mm}$, and the tensile speed was $2 \mathrm{~mm} / \mathrm{min}$. The tensile fracture was analyzed using a SEM (Sirion 200). The thermal conductivity $(\lambda)$ of the alloys was calculated using Equation (1):

$$
\lambda(T)=\alpha \times C_{p} \times \rho,
$$

where $\alpha$ is the thermal diffusivity (measured by laser thermal conductivity meter, LFA457), $C_{p}$ is the specific heat (measured by DSC, NETZSCH STA 449 C, Selb, Germany), and $\rho$ is the density (measured by Archimedes principle). The resistivity was measured using an eddy current conductivity meter (Sigma 2008, Xiamen, China). The equivalent circle diameter (d) and aspect ratio (A.R) of the Si particles were calculated using Equations (2) and (3):

$$
\begin{aligned}
& d=\frac{1}{m} \sum_{j=1}^{m}\left(\frac{1}{n} \sum_{i=1}^{n} \sqrt{\frac{4 \times A_{i}}{\Pi}}\right) \\
& A . R=\frac{1}{m} \sum_{j=1}^{m}\left(\frac{1}{n} \sum_{i=1}^{n}\left(\frac{a_{i}}{b_{i}}\right)\right),
\end{aligned}
$$

where $A, a$, and $b$ are area, major axis, and minor axis of the equivalent ellipse of Si particle, respectively. They were measured by Image-Pro Plus (Media Cybernetics, Bethesda, Rockville, MD, USA). $N$ is the number of particles in each optical micrograph, and $m$ is the number of micrographs. To ensure the accuracy of statistical data, 10 fields of view were selected for each sample.

\section{Results and Discussion}

\subsection{Microstructure}

The optical microstructures of the as-cast and heat-treated alloys are shown in Figure 1. For the as-cast alloys, the Si particles in the unmodified alloy were plate-like and needlelike, whereas, as the $\mathrm{Sb}$ content increased, the size of the Si particles decreased. When the $\mathrm{Sb}$ content was $0.4 \mathrm{wt}$. \% (Alloy-3), partial spherical Si particles appeared in alloys, while the rest were still needle-like. For heat-treated alloys, the edges of the Si particles in the four alloys became obviously rounded, and the average length of Si particles decreased significantly after solution treatment for $8 \mathrm{~h}$. When the solution treatment time increased to $32 \mathrm{~h}$, part of the small particles disappeared, while other particles coarsened significantly and further spheroidized. Therefore, spheroidization and coarsening are two obvious evolution mechanisms of Si particles during solution treatment.

The secondary electron morphology of Si particles is shown in Figure 2. In the deepetched samples, the 3D morphology of Si particles can be obtained, which shows more details that cannot be characterized by optical microstructure. It can be seen in Figure 2 that the Si particles in the Sb-modified alloys (Figure 2c,e,g) are of smaller sizes and have more branches than the unmodified alloy (Figure 2a), but they are still plate-like with sharp edges. This is because the $\mathrm{Sb}$ element can induce the formation of twins in Si particles and make them fine [19]. After solution treatment for $32 \mathrm{~h}$, the morphology of Si particles in different alloys varied greatly: in the non-chemically modified alloy, most $\mathrm{Si}$ particles were long and rod-shaped after solution treatment and some were still plate-like (Figure 2b); in the Sb-modified alloys, the Si particles were short rod-shaped, spherical, and polyhedral (Figure $2 \mathrm{~d}, \mathrm{f}, \mathrm{h}$ ), which indicates that thermal modification is more effective for Sb-modified alloys than unmodified alloys. 


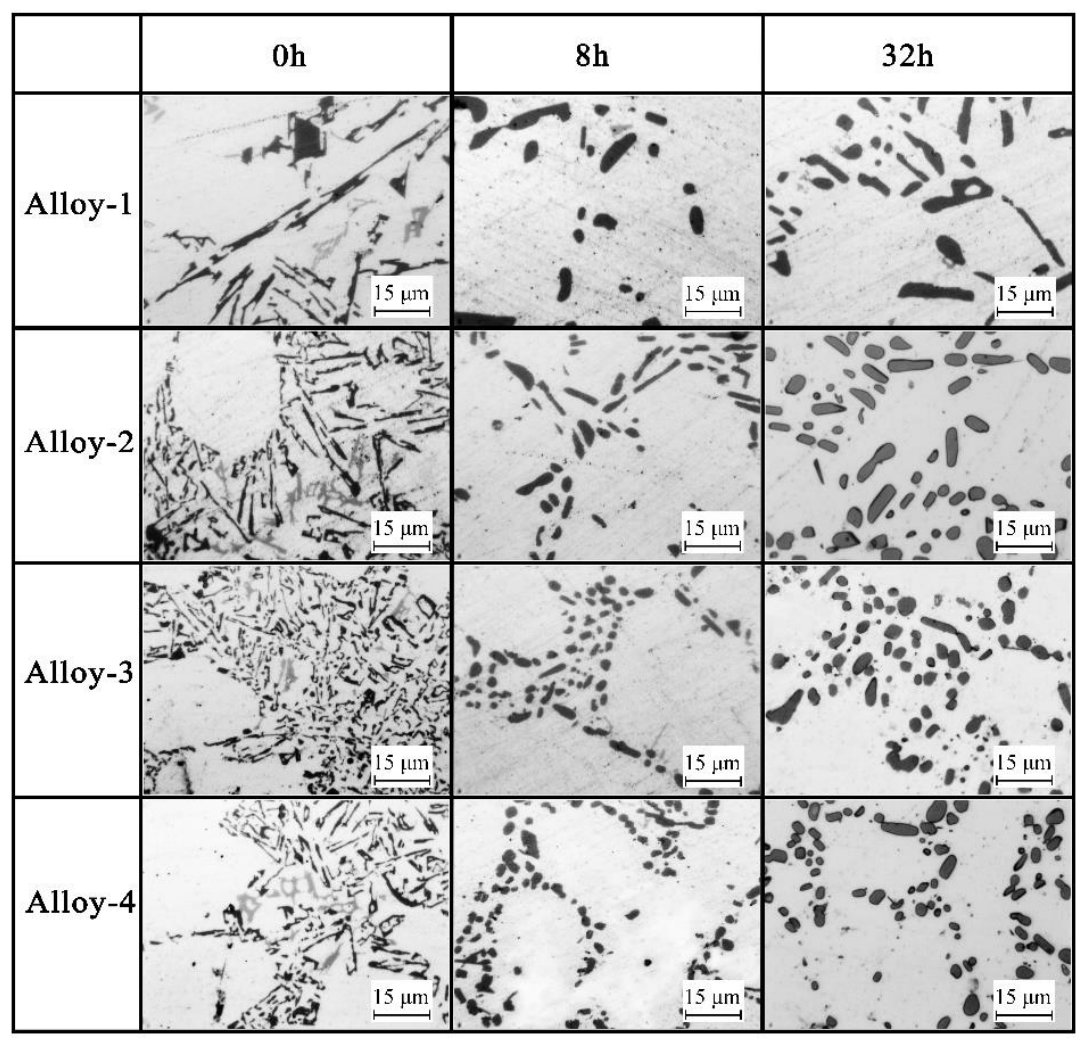

Figure 1. Optical microstructure of the alloys with different solution treatment times at $540{ }^{\circ} \mathrm{C}$.

The high magnification secondary electron images of the Si particles during the solution treatment are shown in Figure 3, which more intuitively shows the other two evolution mechanisms. Figure $3 \mathrm{a}-\mathrm{c}$ show the third kind of evolution mechanism: necking and splitting of particles with large aspect ratios. The necking mainly occurs in the weak spots and branches of Si particles with large aspect ratios. As shown by the yellow arrow in Figure $2 \mathrm{a}, \mathrm{c}, \mathrm{e}, \mathrm{g}$, the large-size Si particles have more branches and faults, especially in Sb-modified alloys. The surface curvature and lattice distortion of these branches and faults positions are large, and they are in an active high-energy state. When heat treatment provides a sufficient driving force, the branches of the particles gradually become rounded and split [21]. However, in the unmodified alloy, after a long solution treatment time, the surfaces of the Si particles become smooth, which reduces the heterogeneity of the surface energy and makes it difficult to break. As a result, the degree of spheroidization of $\mathrm{Si}$ particles was still low after $32 \mathrm{~h}$ solution treatment, and the Si particles evolved into a long rod shape. These results are consistent with those of M. H. Abdelaziz, who proved that the Si particles in unmodified alloys are still long and rod-shaped, even after $400 \mathrm{~h}$ solution treatment [15].

The fourth evolution mechanism is the fusion of spherical particles as shown in Figure $3 \mathrm{~d}-\mathrm{f}$, which mainly occurs between the highly-spheroidized small-size Si particles. The spheroidized small Si particles are very close to each other and even squeeze each other. Under the action of diffusion, fusion gradually occurs, forming the fusion neck as shown in Figure $3 \mathrm{~d}-\mathrm{f}$ (marked by the blue arrow). In particular, there is a distinct fusion line in the fusion neck, which is different from the dissolved neck in Figure 3a-c. This is consistent with the characteristics of the second phase of the highly spheroidized $\mathrm{Pb}-\mathrm{Sn}$ alloys [22]. As shown in Figure 3g, some Si particles have not begun to fuse after squeezing in the alloy, and there are dents on the surface caused by squeezing with other particles (marked by green arrows). In Figure 3d,h, holes on the Si particles (marked by red arrows) can be seen, these are caused by impurity elements, such as Ti and Fe, and have nothing to do with the evolution of Si particles [23]. 

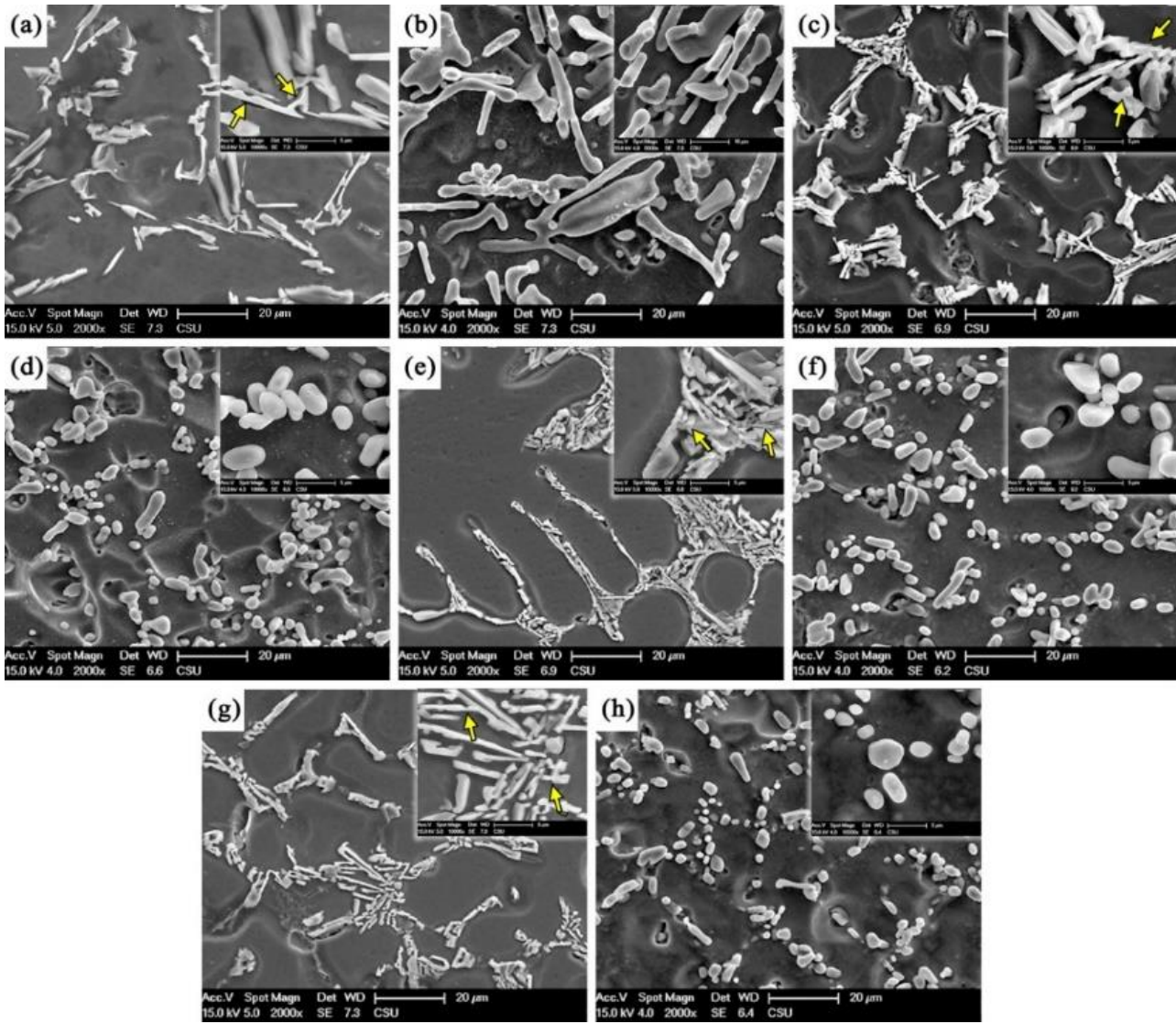

Figure 2. Secondary electron morphology of Si particles in four as-cast and $32 \mathrm{~h}$ solution-treated alloys. (a) As-cast Alloy-1, (b) Solution-treated Alloy-1, (c) As-cast Alloy-2, (d) Solution-treated Alloy-2, (e) As-cast Alloy-3, (f) Solution-treated Alloy-3, (g) As-cast Alloy-4, (h) Solution-treated Alloy-4.

In summary, there are four evolution mechanisms of Si particles during solution treatment: spheroidization, splitting, fusion, and coarsening. However, not every mechanism has a significant and positive effect on the properties of the alloys. Therefore, it is necessary to determine the action time of each mechanism and formulate a reasonable heat treatment system for Al-Si alloys. The spheroidization of Si particles has been widely demonstrated: the decrease of surface energy is its main driving force, and it usually occurs in a relatively short time $(<1 \mathrm{~h})$ [23]. In the following sections, splitting, fusion, and coarsening will be discussed.

Since splitting and fusion occur in large-sized and small-sized particles, respectively, the equivalent diameter and its distribution of Si particles at different solution heat treatment time were calculated, respectively, as shown in Figure 4. It should be noted that the size of the Si particles in the Sb-modified alloys is smaller, so the interval division of size is denser. The broken lines show that, with increasing solution treatment time, the $\mathrm{Si}$ particle size of Alloy- 1 and Alloy-2 decreased slightly at first and then increased gradually, while the Si particle size continued to coarsen and grow in Alloy-3 and Alloy-4. Both the yellow and blue columns, which represent the large-size Si particles, decrease first and then increase. This indicates that lots of large-size Si particles fracture at the initial stage of solution treatment. The fracturing speed of Si particles is much higher than the coarsening speed, which leads to the transformation of lots of large-size Si particles into small-size Si particles. After solution treatment for $4 \mathrm{~h}$ or longer, the yellow and blue columns increased steadily, indicating that necking and splitting were no longer effective. For the small-sized Si particles, the change of content during the solution process were random, which may be the result of the competition between the splitting and fusion. At the same time, the action time of the fusion could not be determined. However, after a long period of solution 
treatment time (e.g., $32 \mathrm{~h}$ ), the small size of Si particles decreased significantly, which may be related to the Ostwald ripening mechanism.
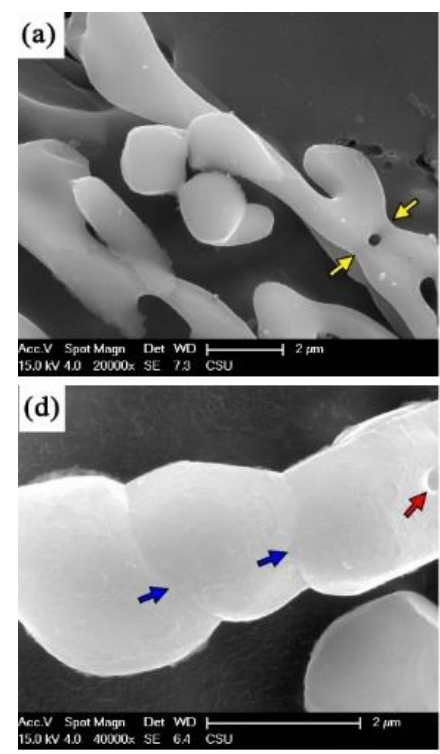

(g)

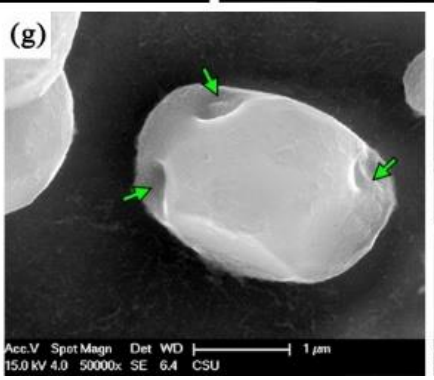

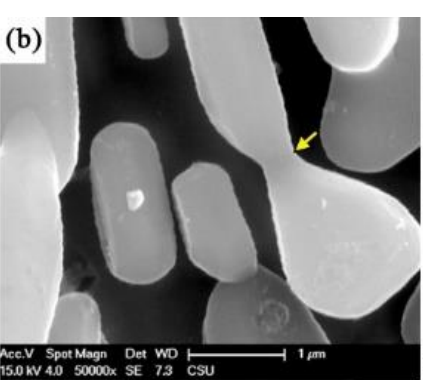

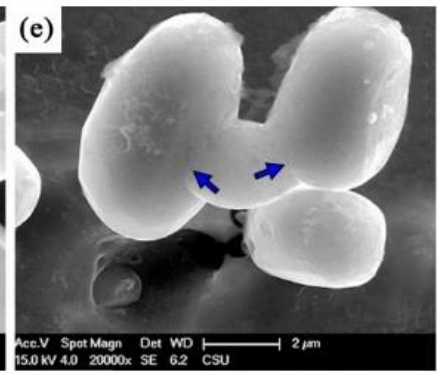

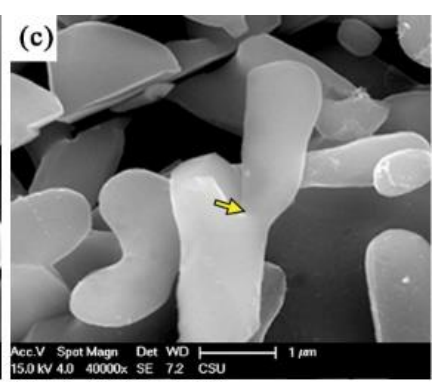

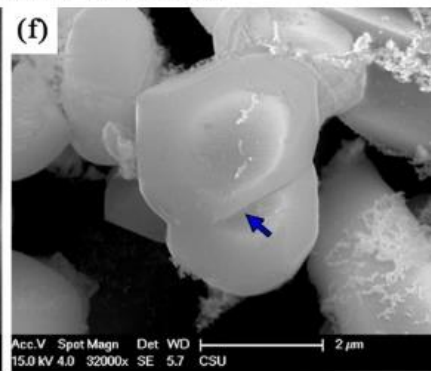

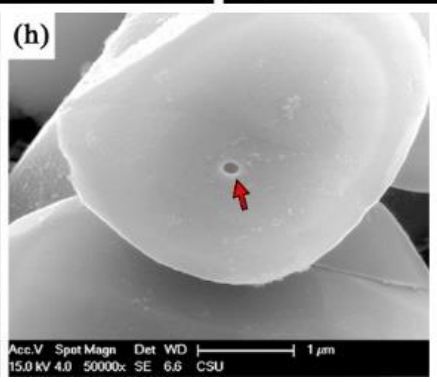

Figure 3. High-magnification secondary electron image of Si particles. (a) Alloy-2 for $4 \mathrm{~h}$, (b) Alloy-3 for $1 \mathrm{~h}$, (c) Alloy-4 for $4 \mathrm{~h}$, (d) Alloy-2 for $4 \mathrm{~h}$, (e) Alloy-3 for $1 \mathrm{~h}$, (f) Alloy-4 for $8 \mathrm{~h}$, (g) Alloy-4 for $32 \mathrm{~h}$, (h) Alloy-4 for $4 \mathrm{~h}$.

Because the growth rate of coarsening controlled by the Ostwald ripening mechanism is a constant, if the growth rate is higher than the stable value at any point, particle fusion occurs. Therefore, the action time of the fusion can be determined by calculating the growth rate of the average particle size. The constant can be calculated from the following equation [24]:

$$
r^{3}-r_{0}^{3}=K_{L S W} \times t,
$$

where $K_{L S W}$ is the constant related to temperature and surface energy, $r_{0}$ is the initial radius of the particle, $r$ is the average radius of the particles after solution treatment (as shown in Figure 4 ), and $t$ is the time of solution treatment.

The fusion can be determined by calculating the growth rates of prophase and anaphase. For Alloy-1 and Alloy-2, $K_{L S W}$ cannot be calculated because of the decline of particle radius within $1 \mathrm{~h}$, so the diffusion constants of 1-4 h and 4-32 $\mathrm{h}$ were calculated as the growth rate of prophase and anaphase, respectively. For Alloy-3 and Alloy-4, the diffusion constants of $0-1 \mathrm{~h}$ and $1-32 \mathrm{~h}$ were calculated, respectively. The calculation results are shown in Table 2, in which the $K_{L S W}$ mean growth rate of prophase and the $K_{L S W^{-}}-2$ mean growth rate of anaphase are displayed. It is obvious that $K_{L S W^{-}}-1$ is much larger than $K_{L S W}-2$, which means that particle coalescence plays a major role in the early stage. With the increase of solution time, the distance between Si particles gradually increases, and the coalescence of particles gradually becomes negligible. Meanwhile, compared with the Sb-free alloys, both $K_{L S W^{-}}-1$ and $K_{L S W^{-}}-2$ of Sb-modified alloys significantly decline. This is 
related to the decrease of the proportion of Si particles with high surface energy, which is caused by the spheroidization of modified Si particles.
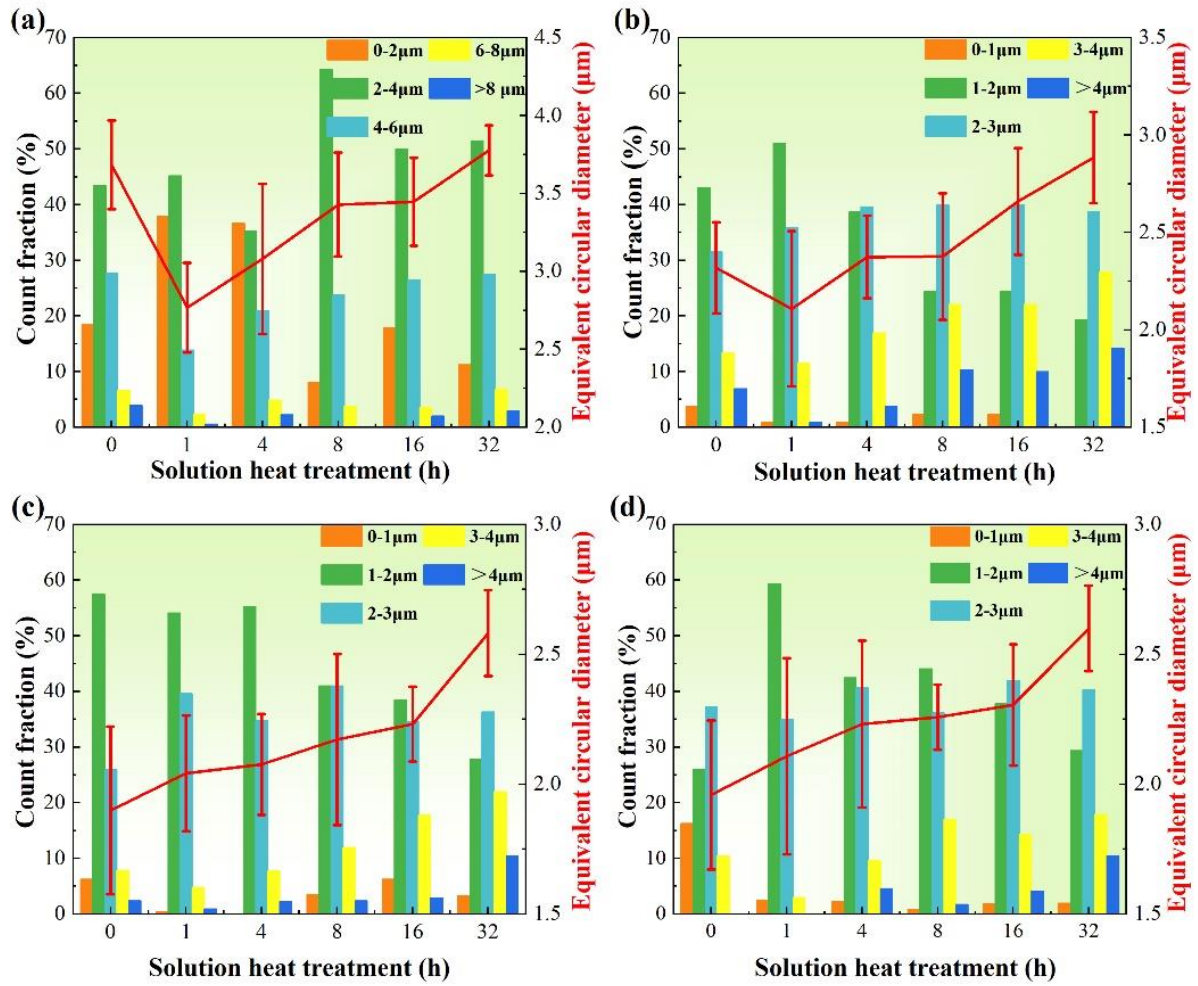

Figure 4. Equivalent circle diameter and its distribution of Si particles during solution treatment at $540{ }^{\circ}$ C. (a) Alloy-1, (b) Alloy-2, (c) Alloy-3, (d) and Alloy-4.

Table 2. Calculated value of $K_{L S W^{-1}}$ and $K_{L S W^{-}}-2$.

\begin{tabular}{cccc}
\hline Code & Alloy & $K_{L S W^{-1}}$ & $K_{L_{S W} \mathbf{- 2}}$ \\
\hline Alloy-1 & Al-8Si-0.6Mg-0Sb & 0.3347 & 0.0961 \\
Alloy-2 & Al-8Si-0.6Mg-0.2Sb & 0.1252 & 0.0489 \\
Alloy-3 & Al-8Si-0.6Mg-0.4Sb & 0.2079 & 0.0347 \\
Alloy-4 & Al-8Si-0.6Mg-0.6Sb & 0.2107 & 0.0304
\end{tabular}

At the early stage of solution treatment, the splitting of large particles, fusion of small particles, and passivation of edges are very active. As faults and branches break and the edges become rounded, the surface energy of each particle tends to stabilize, resulting in the splitting and spheroidization being almost complete. At the stable stage, the Si particles close to each other coalesce, and the Ostwald ripening mechanism controlled by diffusion plays a leading role. In addition, the Sb element plays an important role in the evolution of thermal modification. Since the chemically modified and large-size particles have more branches and faults, necking and separation are more effective. The more small particles that are obtained by splitting and chemical modification, the more obvious the spheroidization and coalescence. Moreover, the chemical modification leads to an improvement in the morphology of the Si particles and decreases in the surface energy of the Si particles, so the addition of $\mathrm{Sb}$ effectively reduces the growth rate of Si particles controlled by diffusion. 


\subsection{Thermal Conductivity}

Figure 5 shows the thermal conductivity and resistivity curves of alloys during solution treatment at $540{ }^{\circ} \mathrm{C}$. Modification has positive effects on the thermal conductivity of alloys. The thermal conductivity gradually increases with the extension of the heat treatment time, but the increasing amplitude gradually decreases until it reaches a stable plateau at $8 \mathrm{~h}$.

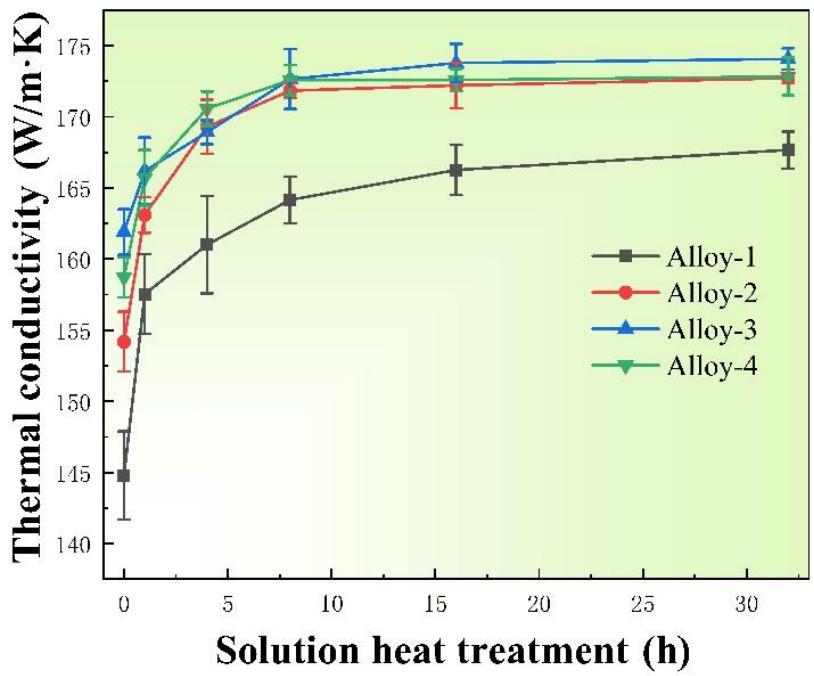

Figure 5. Thermal conductivity of alloys during solution treatment.

The thermal conductivity of materials is determined by both phonons and electrons. In Al-Si alloys, the influence of phonons on the thermal conductivity needs to be discussed from the aspects of the $\mathrm{Si}$ particles and the $\mathrm{Al}$ matrix. The vacancies and lattice distortion caused by solution heat treatment increase the scattering probability and reduce the mean free path of the phonons. However, the contribution of the phonons to the thermal conductivity of the $\mathrm{Al}$ matrix is less than $5 \%$ [25], which means that phonons do not cause a significant change in the thermal conductivity of the $\mathrm{Al}$ matrix. Therefore, the effect of phonons on the thermal conductivity of materials is mainly related to Si particles. The phonon is the decisive factor in terms of the thermal conductivity of Si. The Si particles are significantly spheroidized by thermal modification, which reduces the total interface length to improve the coordination of phonon propagation. Therefore, thermal modification is beneficial to phonon propagation; it improves the uniformity of the structure and reduces the interface area between $\mathrm{Al}$ and $\mathrm{Si}$, which helps reduce the anharmonicity of lattice vibration and lattice wave scattering [26].

The influence of electrons on thermal conductivity is related to electron movement. The vacancies and lattice distortion caused by a high-temperature solution reduce the electron movement, but the improvement of Si particle morphology and the disappearance of the intermetallic are favorable for electron diffusion. In general, the movement of electrons in the metal can be quantitatively described by resistivity. Figure 6 shows the resistivity of alloys during solution treatment. It can be seen that thermal modification significantly reduces the resistivity, and, with the increase of solution time, the resistivity gradually stabilizes. According to the Matthiessen-Flemming principle (Equation (5)), the total resistivity $(\rho)$ of the alloy is related to many factors $[27,28]$. 


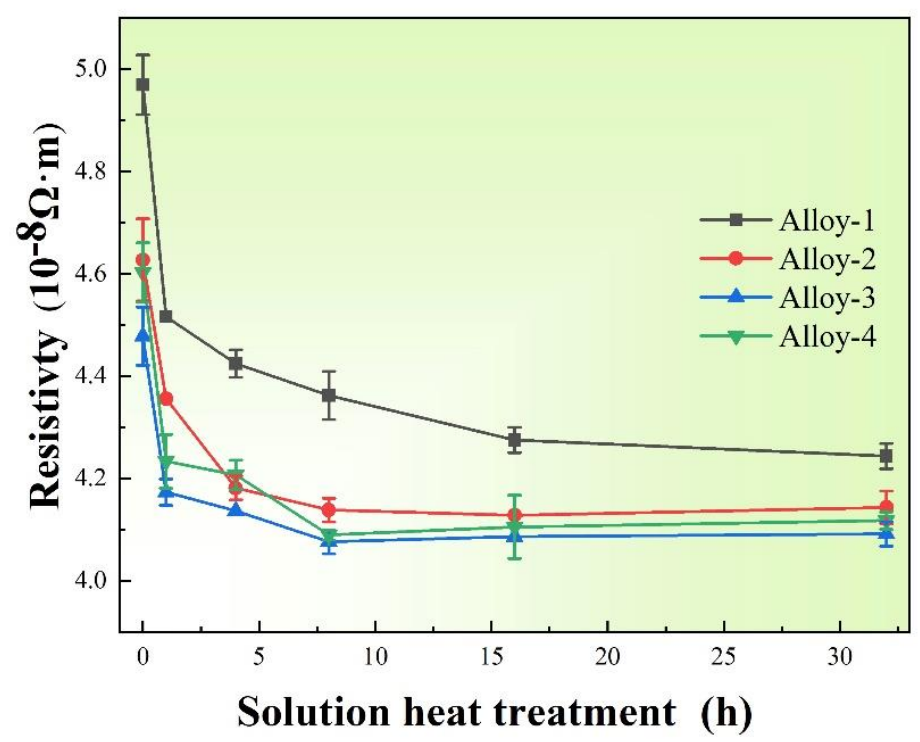

Figure 6. Resistivity of alloys during solution treatment.

$$
\rho=\rho^{\text {Alpure }}+\triangle \rho^{p-p}+\triangle \rho^{S i}+C_{v} \times \triangle \rho^{V A C}+S_{G B} \times \triangle \rho^{G B}+\sum_{i} C_{\text {solu }}^{i} \times \triangle \rho_{\text {solu }}^{i}
$$

where $\rho^{\text {Alpure }}$ is the resistivity of pure $\mathrm{Al}\left(\sim 2.655 \times 10^{-8} \Omega \cdot \mathrm{m}\right)$, and $\triangle \rho^{p-p}, \triangle \rho^{S i}, \triangle \rho^{V A C}$, $\triangle \rho^{G B}$, and $\triangle \rho_{\text {solu }}^{i}$ are the resistivity values of the precipitated phases, Si particles, vacancies, grain boundaries, and solute elements, respectively. $C_{v}$ and $C_{\text {solu }}^{i}$ are the vacancy and solute concentration, respectively. $S_{G B}$ is related to the grain size and calculated from the formula $S_{G B}=\frac{6}{\bar{d}}$, where $\bar{d}$ is the average grain size. In this work, each crystal grain contains many dendrites, so the dendrite spacing is regarded as $\bar{d}$.

Due to the finite growth of grains at high temperatures [29], the data calculated by Yoji Miyajima (i.e., $\triangle \rho^{G B}=2.6 \times 10^{-16} \Omega \cdot \mathrm{m}^{2}$ ) can quantify the effect of grain boundary changes on electrical conductivity [30]. The contribution of grain boundaries to the electrical resistivity of alloys before and after solutionizing were calculated, and the results are shown in Table 3. In the table, $S_{G B-C a s t}$ and $S_{G B-S T}$ represent the fraction of grain boundary per unit volume of cast alloys and solution-treated alloys, respectively. It can be seen that the decrease in conductivity through grain growth does not exceed $1 \%$ of the resistivity of pure aluminum, which is extremely limited.

Table 3. Contribution of grain boundaries to the electrical resistivity of alloys before and after solutionizing.

\begin{tabular}{ccc}
\hline Code & $\left|S_{G B-\text { Cast }}-S_{G B-S T}\right| \triangle \rho^{G B}\left(\Omega \cdot \mathrm{m} / 10^{-11}\right)$ & $\triangle S_{G B} \triangle \rho^{G B} / \rho^{\text {Alpure }}$ (\%) \\
\hline Alloy-1 & 1.13 & 0.50 \\
Alloy-2 & 1.24 & 0.47 \\
Alloy-3 & 1.82 & 0.69 \\
Alloy-4 & 1.24 & 0.47 \\
\hline
\end{tabular}

The vacancy concentration is temperature-dependent, and quenching retains lots of vacancies generated by high temperature, according to the vacancy concentration balance formula [31]:

$$
C_{v}=A \times \exp \left(-\frac{\mu}{k T}\right)
$$

where $\mu$ is the vacancy formation energy $(\sim 0.76 \mathrm{eV}), k$ is the Boltzmann constant $\left(\sim 8.62 \times 10^{-5} \mathrm{eV} / \mathrm{K}\right)$, $A$ is the material constant $(\sim 1)$ and $T$ is the solution temperature $(\sim 813 \mathrm{~K})$. Using this equation, we calculated $C_{v}=1.95 \times 10^{-5}$. Reference [27] shows that when the vacancy concentration increases 
to $10^{-3}$, the resistivity only increases to $2.6 \times 10^{-11} \Omega \cdot \mathrm{m}$, which means that the effect of vacancies caused by solution treatment is negligible.

Considering that the scattering effect of second phase particles (such as $\mathrm{Mg}_{2} \mathrm{Si}$ ) on electrons is much lower than that when they are dissolved in the matrix [18], $\rho^{p-p}$ decreases slightly and $\triangle \rho_{\text {solu }}^{i}$ increases significantly during solution treatment. Therefore, the significant reduction of resistivity is attributed to the decrease in $\rho^{S i}$. During the solution treatment, the morphology of Si particles changes, which will show different blocking effects on electrons, indicating that the evolution mechanism of Si particles has an impact on the conductivity.

As Figures 1 and 2 show, the evolution of Si particles is mainly due to the change of the aspect ratio and the number of particles. To explore the influence of each evolution mechanism on $\rho^{S i}$, Python was used to build rectangular Si particle distribution models with different aspect ratios (A.R) and numbers of particles. The models are based on the following three rules: (1) The proportion of the Si particle area is $8 \%$; (2) The orientation and position of each Si particle are completely random; and (3) The overlapping area between particles does not exceed 5\%. The randomly constructed shape is shown in Figure 7.

Assuming that electrons pass through the above-mentioned shape horizontally, the movement of scattered electrons can be ignored. The electron passing rate was calculated, and a contour map was drawn, as shown in Figure 8, which can characterize the influence of these factors on the conductivity. The Figure 8 shows that the scattering effect of particles on electrons is positively correlated with the number of particles and the aspect ratio. In addition, the effect of the number of particles is stronger. Particle coalescence can significantly reduce the number of particles without significantly increasing the aspect ratio of the particles, which is beneficial to increase the electron pass rate. Similarly, the spheroidization of particles can effectively reduce the aspect ratio without changing the number of particles, which means that spheroidization has a strong positive effect on conductivity. Under the premise of ignoring the spheroidization of particles, splitting reduces the aspect ratio of the particles but significantly increases the number of particles, which is detrimental to the electron pass rate. However, more importantly, particle fragmentation provides more particles with a low aspect ratio which are easier to spheroidize and coalesce, thereby further catalyzing the increase in electrical conductivity. Coarsening has a lower effect on the aspect ratio. Although the Ostwald ripening mechanism can reduce the number of fine particles, the interception of electrons by the fine Si particles is limited. Therefore, the resistivity at the stable stage seems to be a constant.

\subsection{Mechanical Properties}

Since the thermal conductivity reaches a stable plateau after $8 \mathrm{~h}$ of solution treatment, $8 \mathrm{~h}$ is considered to be the best heat treatment time. Then, the mechanical properties of T4 and T6 heat treatment were tested. The tensile strength and elongation values of the alloys before and after heat treatment are shown in Table 4. As the strength and elongation of the alloys vary greatly in different states, the quality index chart, which is commonly used to evaluate the comprehensive properties of cast aluminum, is used to compare the performance differences [32]. The quality index diagram includes the elongation and strength after fracture and the quality index Q, which are calculated by [33]:

$$
Q=U T S+150 \times \lg (\delta),
$$

where UTS is the tensile strength, and $\delta$ is the elongation after fracture. 

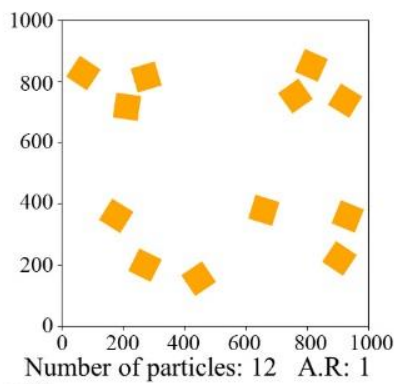

1000

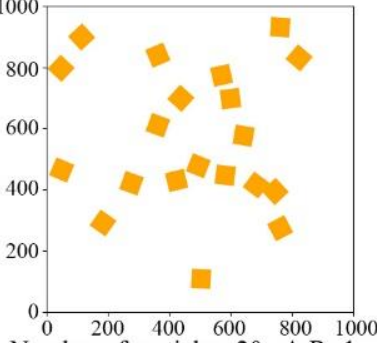

Number of particles: 20 A.R: 1

1000

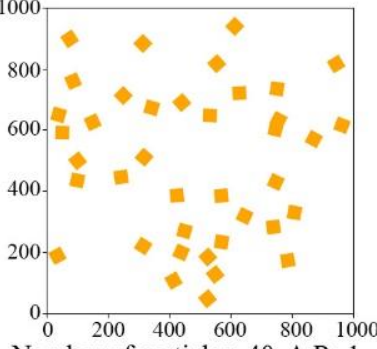

Number of particles: 40 A.R: 1
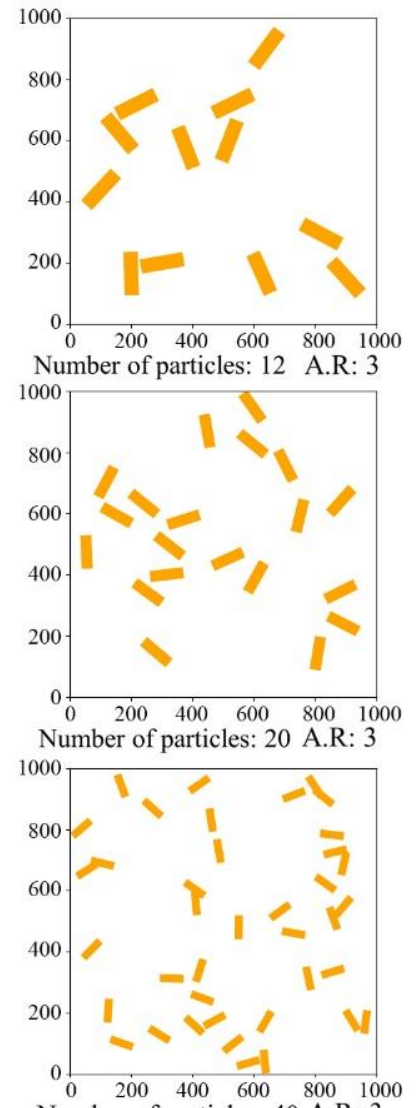

Number of particles: 40 A.R: 3

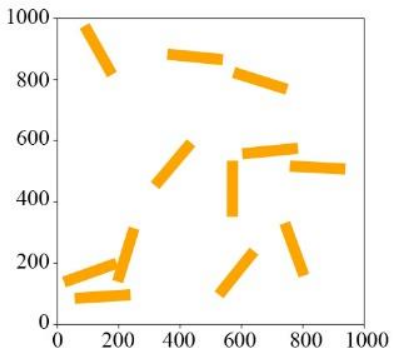

Number of particles: 12 A.R: 5

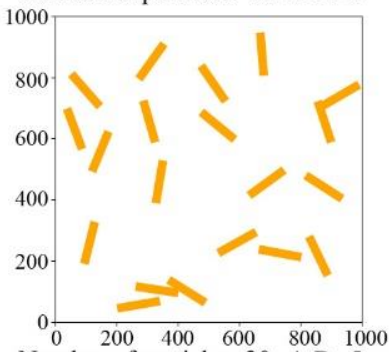

Number of particles: 20 A.R: 5

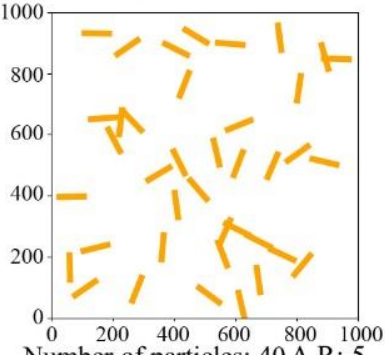

Figure 7. Simplified model of Si particle distribution with different particle numbers and aspect ratios (A.R) constructed by Python.

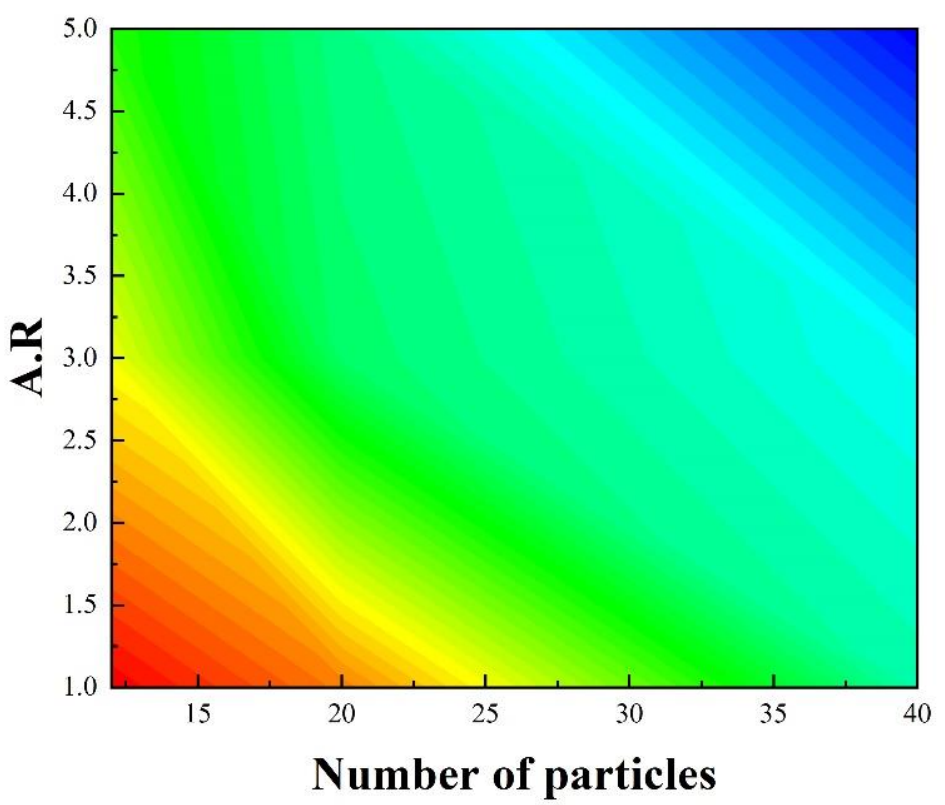

\section{Electron pass rate}

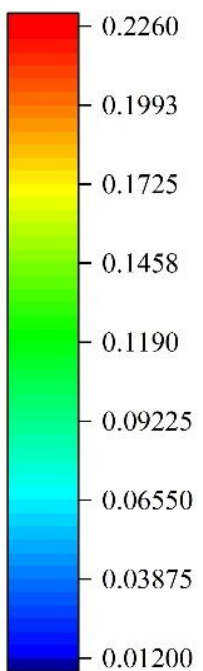

Figure 8. Contour map of the electron pass rate with respect to the aspect ratio (A.R) and the number of particles. 
Table 4. Tensile mechanical properties of the alloys before and after heat treatment.

\begin{tabular}{ccccc}
\hline Condition & Alloy & YS (MPa) & UTS (MPa) & EL (\%) \\
\hline \multirow{3}{*}{ As-cast } & Alloy-1 & $117.3 \pm 10.9$ & $187.1 \pm 15.3$ & $4.5 \pm 0.6$ \\
& Alloy-2 & $120.6 \pm 9.6$ & $190.2 \pm 17.6$ & $5.7 \pm 0.4$ \\
& Alloy-3 & $123.1 \pm 5.4$ & $205.7 \pm 18.1$ & $6.2 \pm 0.6$ \\
& Alloy-4 & $119.4 \pm 6.7$ & $194.4 \pm 12.4$ & $6.0 \pm 0.8$ \\
\hline \multirow{2}{*}{ T4 } & Alloy-1 & $78.2 \pm 8.3$ & $164.9 \pm 13.2$ & $8.9 \pm 1.2$ \\
& Alloy-2 & $82.2 \pm 4.6$ & $166.4 \pm 9.6$ & $12.7 \pm 1.6$ \\
& Alloy-3 & $87.5 \pm 5.1$ & $181.2 \pm 14.3$ & $18.4 \pm 0.8$ \\
& Alloy-4 & $80.4 \pm 6.0$ & $174.4 \pm 11.0$ & $16.2 \pm 1.4$ \\
\hline \multirow{2}{*}{ T6 } & Alloy-1 & $179.9 \pm 11.8$ & $237.5 \pm 17.3$ & $4.2 \pm 0.7$ \\
& Alloy-2 & $169.6 \pm 7.5$ & $242.0 \pm 10.7$ & $5.6 \pm 0.6$ \\
& Alloy-3 & $174.7 \pm 6.2$ & $256.8 \pm 12.9$ & $9.1 \pm 1.2$ \\
& Alloy-4 & $178.8 \pm 5.7$ & $247.7 \pm 14.7$ & $8.1 \pm 0.9$ \\
\hline
\end{tabular}

As shown in Table 4 and Figure 9, the modification of $\mathrm{Sb}$ and heat treatment have positive effects on mechanical properties, especially the $0.4 \%$ Sb-modified alloys (Alloy-3), which show better comprehensive mechanical properties than other alloys. After chemical modification by $0.4 \% \mathrm{Sb}$, the $\mathrm{Q}$ index of the as-cast alloys increased from $285.1 \mathrm{MPa}$ to $324.6 \mathrm{MPa}$ with an increase rate of $13.8 \%$. After solution heat treatment (T4), the strength decreased slightly and the elongation increased greatly, the comprehensive properties of the alloys improved significantly, and the Q index of Alloy-3 increased from $324.6 \mathrm{MPa}$ (as-cast) to $370.1 \mathrm{MPa}$ (T4). The ability of Sb to improve the properties of Al-Si-Mg alloy was further enhanced by solution treatment, which is due to the strong improvement of microstructure of Sb-modified alloy by thermal modification. After $7 \mathrm{~h}$ of artificial aging (T6), the strength of the alloys increased, the elongation decreased, the comprehensive properties improved slightly, and the Q index of Alloy-3 increased to $400.6 \mathrm{MPa}$.

Figure 10 shows the micrographs of tensile fracture surfaces of the as-cast alloys. The fracture surface of Alloy-1 is mainly a cleavage fracture and contains lots of tearing edges, showing obvious brittle fracture characteristics. With the enhancement of the $\mathrm{Sb}$ modification effect, the cleavage plane area decreases, and the tearing edge increases. There are a lot of cracks in the Si particles, which show obvious characteristics of transgranular fractures. After solution treatment for $8 \mathrm{~h}$, the fracture modes of Alloy- 1 and Alloy-2 changed from brittle fractures to ductile-brittle mixed fractures, and the others all changed to ductile fractures. The fractures consist of a large number of equiaxed dimples and $\mathrm{Si}$ particles. When the alloy is modified by $0.4 \mathrm{wt} . \% \mathrm{Sb}$, the as-solution fracture mode of the Si particles changes to an intergranular fracture, the dimples are deep and dense, and the ductility of the alloy reaches the best value.

Figure 11a,b show the metallographic microstructure near the fracture of Alloy-3 before and after solution treatment, and some cracks near the fracture are marked by yellow circles in the figure. In Figure 11a, the cracks at the as-cast alloy are mainly caused by needle-like Si particles. Si particles with large aspect ratios are difficult to coordinate with the deformation of the matrix during the tensile process. The stress concentration at the sharp corners leads to the germination of microcracks. According to the fiber reinforcement theory, the stress in the center of the particle is proportional to the shear stress in the matrix [34]. Therefore, the higher stress in the Si particles with large aspect ratios leads to the transgranular fracture of the as-cast Si particles, which also promotes the formation of microcracks. However, this does not explain why the well-spheroidized particles in Figure 10b still have cracks inside them. Yang's research reveals that the second phase with a similar shape but a larger size difference is subjected to different stresses during the tensile process, while the larger particles are subjected to greater internal stresses during 
deformation [35]. According to Griffith's theory, the fracture stress of the second phase particle is inversely proportional to the particle radius $[36,37]$ :

$$
\sigma_{c}=k_{c} \times d^{-1 / 2},
$$

where $k_{c}$ is the fracture toughness of particles and $d$ is the average diameter of the particles.

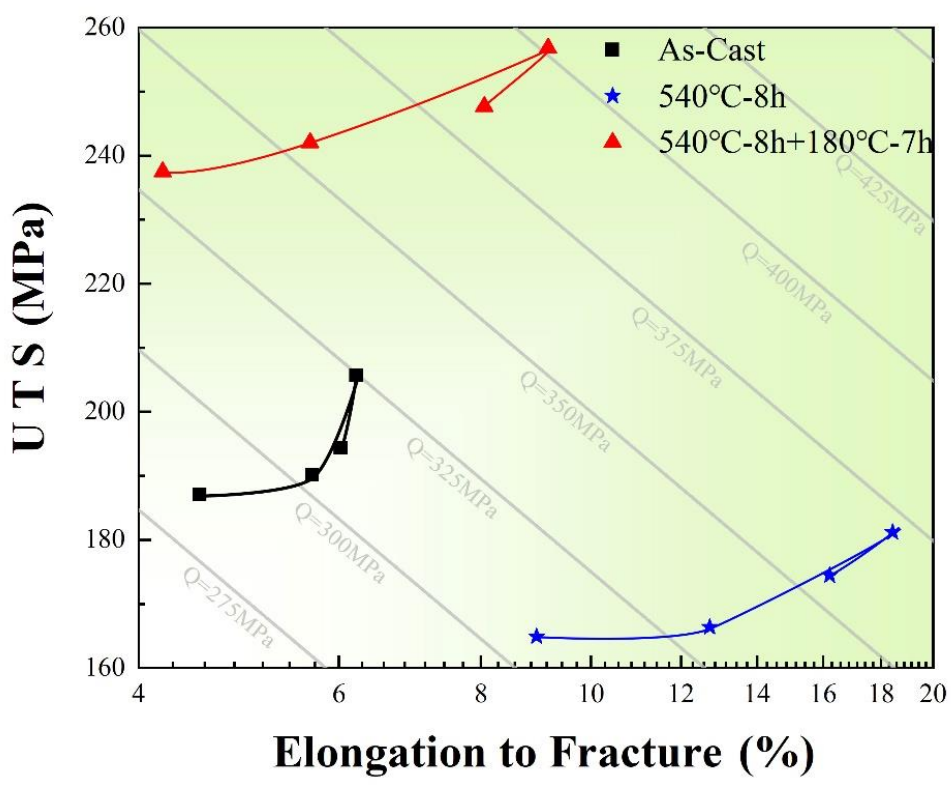

Figure 9. The quality index chart of alloys in different states.
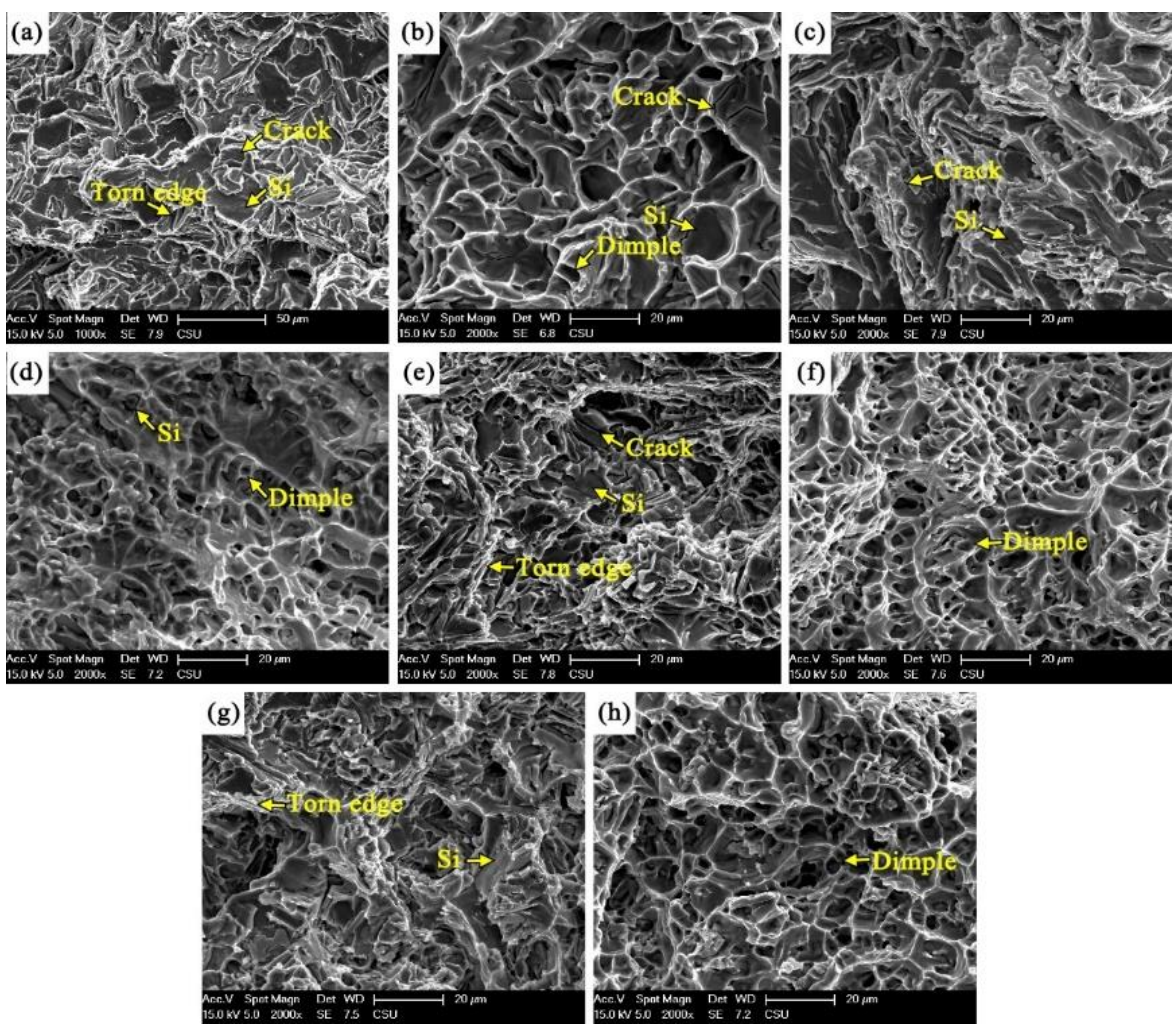

Figure 10. SEM fracture morphology of as-cast and as-solution alloys. (a) As-cast Alloy-1, (b) Assolution-treated Alloy-1, (c) As-cast Alloy-2, (d) As-solution-treated Alloy-2, (e) As-cast Alloy-3, (f) As-solution-treated Alloy-3, (g) As-cast Alloy-4, (h) As-solution-treated Alloy-4. 

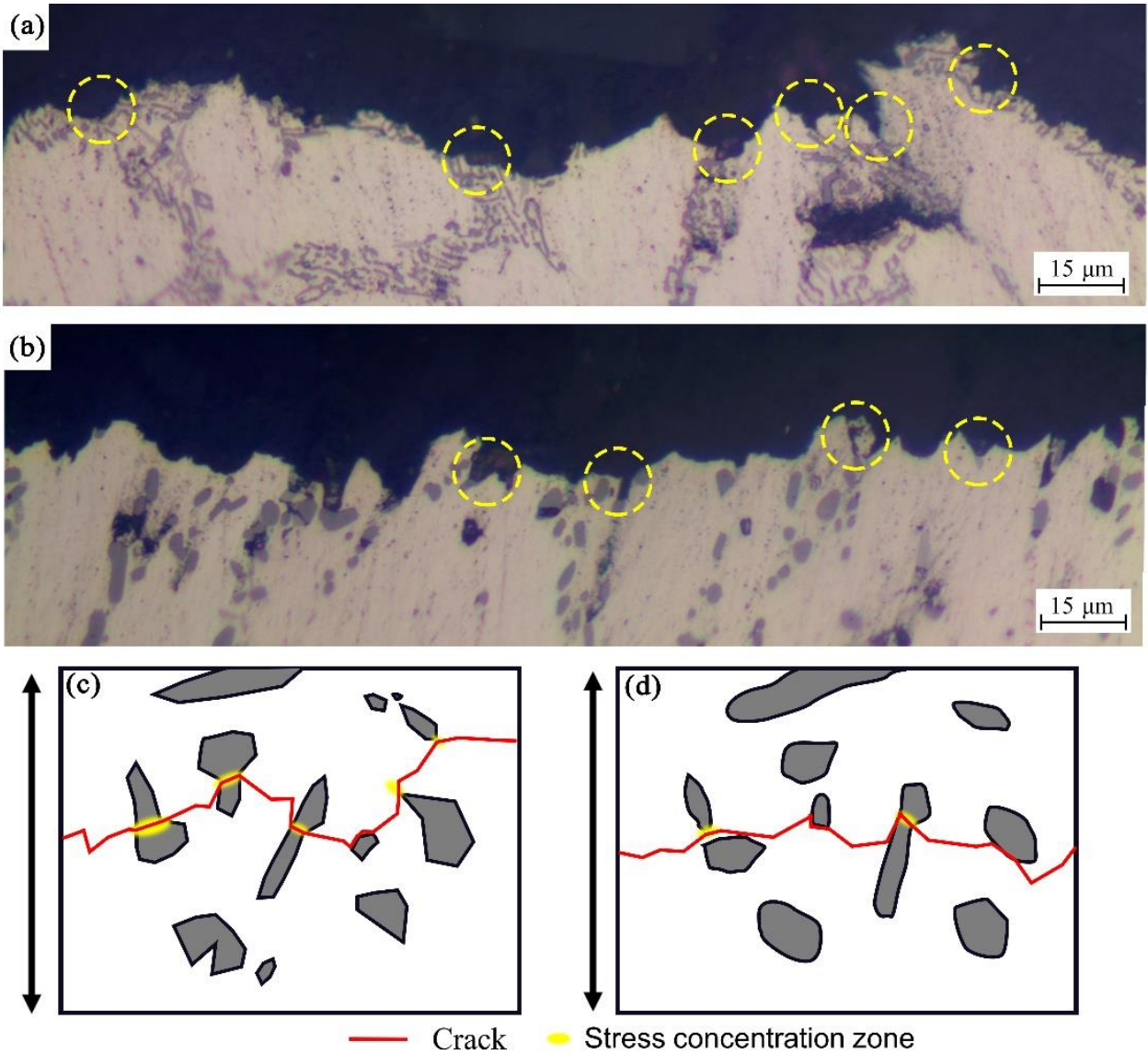

Figure 11. Crack optical micrographs, $(\mathbf{a}, \mathbf{b})$, and models, $(\mathbf{c}, \mathbf{d})$, of the fracture behavior of Alloy-3 before, $(\mathbf{a}, \mathbf{c})$, and after solution treatment, $(\mathbf{b}, \mathbf{d})$.

After modification, the fine Si particles obtained a higher expected strength value. Therefore, a low aspect ratio, small size, and edge passivation are beneficial to reduce the internal stress of Si particles and the shear stress in the matrix, avoid internal cracking, and reduce the tendency of transcrystalline fracture and the possibility of microcrack germination. Both chemical and thermal modification are beneficial to the formation of the above morphology. Therefore, the simplified models of alloy fracture behavior before and after solution treatment can be expressed in Figure 11c,d.

\section{Conclusions}

This paper discusses the effect of solution treatment on the evolution of Si particles and properties of Sb-modified Al-Si-Mg alloys. Chemical modification has an obvious promoting effect on thermal modification, and the combination of the above two methods can achieve the ideal morphology of Si particles, which is conducive to the determination of the heat treatment system of Al-Si alloys. The following conclusions can be drawn from this research:

(1) There are four evolution mechanisms of Si particles during the solution treatment: spheroidization, splitting, coalescence, and coarsening. Spheroidization, fusion, and coalescence are active at the early stage. The growth of Si particles is a coarsening process controlled by diffusion.

(2) $\mathrm{Sb}$ changes the contribution of each mechanism Si particle, resulting in the thermal modification of the $\mathrm{Sb}$-modified alloy being more effective. This is because the modified Si particles have smaller aspect ratios and more branches and faults, leading to more effective spheroidization and more active fusion and coalescence. 
(3) The improved thermal conductivity of the alloy due to thermal modification benefits from the effect of Si-particle evolution on phonon propagation and electron transport. After solution treatment, the interface length of Si particles decreases, which reduces the anharmonicity of lattice vibration and lattice wave scattering. In addition, the more spheroidized Si particles also provide more channels for electron transport.

(4) The particles treated by chemical modification and thermal modification have a smaller size and better morphology, which reduce the stress in its center and the shear stress in the matrix. Therefore, the crack germination is slowed down, and the alloy achieves higher mechanical properties.

Author Contributions: Conceptualization, X.L. and H.L.; methodology, X.L. and H.L.; validation, Y.W., X.G. and L.Z.; investigation, Y.W. and X.G.; data curation, Y.W. and L.Z.; writing-original draft preparation, Y.W.; writing-review and editing, X.L. and L.W.; supervision, H.L.; funding acquisition, X.L. All authors have read and agreed to the published version of the manuscript.

Funding: This work was funded by the National Key Research and Development Program of China (Grant Nos. 2018YFB2001801) and the Open Sharing Fund for the Large-scale Instruments and Equipment of Central South University.

Data Availability Statement: Data presented in this study are available on request from the corresponding author. Data are not publicly available because pertain to a research still in development.

Acknowledgments: This work was financially supported by the National Key Research and Development Program of China (Grant Nos. 2018YFB2001801) and the Open Sharing Fund for the Large-scale Instruments and Equipment of Central South University.

Conflicts of Interest: The authors declare no conflict of interest.

\section{References}

1. Li, K.; Zhang, J.; Chen, X.; Yin, Y.; Guan, R. Microstructure evolution of eutectic Si in Al-7Si binary alloy by heat treatment and its effect on enhancing thermal conductivity. J. Mater. Res. Technol. 2020, 9, 8780-8786. [CrossRef]

2. Wislei, R.O.; Noé, C.; José, E.S.; Goulart, P.R.; Garcia, A. The effects of a eutectic modifier on microstructure and surface corrosion behavior of Al-Si hypoeutectic alloys. J. Solid State Electrochem. 2007, 11, 1421-1427.

3. Fat-Halla, N. Structural modification of Al-Si eutectic alloy by Sr and its effect on tensile and fracture characteristics. J. Mater. Sci. 1989, 24, 2488-2492. [CrossRef]

4. $\quad$ Reyes, R.V.; Bello, T.S.; Kakitani, R.; Costa, T.A.; Garcia, A.; Cheung, N.; Spinelli, J.E. Tensile properties and related microstructural aspects of hypereutectic Al-Si alloys directionally solidified under different melt superheats and transient heat flow conditions. Mater. Sci. Eng. A 2017, 685, 235-243. [CrossRef]

5. Natori, K.; Utsunomiya, H.; Tanaka, T. Improvement in formability of semi-solid cast hypoeutectic Al-Si alloys by equal-channel angular pressing. J. Mater. Process. Tech. 2017, 240, 240-248. [CrossRef]

6. Gursoy, O.; Timelli, G. Lanthanides: A focused review of eutectic modification in hypoeutectic Al-Si alloys. J. Mater. Res. Technol. 2020, 9, 8652-8666. [CrossRef]

7. Barrirero, J.; Li, J.; Engstler, M.; Ghafoor, N.; Schumacher, P.; Odén, M.; Mücklich, F. Cluster formation at the Si/liquid interface in Sr and Na modified Al-Si alloys. Scripta Mater. 2016, 117, 16-19. [CrossRef]

8. Elgallad, E.M.; Doty, H.W.; Alkahtani, S.A.; Samuel, F.H. Effects of La and Ce addition on the modification of Al-Si based alloys. Adv. Mater. Sci. Eng. 2016, 2016, 1-13. [CrossRef]

9. Farahany, S.; Ourdjini, A.; Bakhsheshi-Rad, H.R. Microstructure, mechanical properties and corrosion behavior of Al-Si-Cu-Zn-X ( $\mathrm{X}=\mathrm{Bi}, \mathrm{Sb}, \mathrm{Sr})$ die cast alloy. Trans. Nonferrous Met. Soc. China 2016, 26, 28-38. [CrossRef]

10. Nampoothiri, J.; Balasundar, I.; Raj, B.; Murty, B.S.; Ravi, K.R. Porosity alleviation and mechanical property improvement of strontium modified A356 alloy by ultrasonic treatment. Mater. Sci. Eng. A 2018, 724, 586-593. [CrossRef]

11. Mao, G.; Yan, H.; Zhu, C.; Wu, Z.; Gao, W. The varied mechanisms of yttrium (Y) modifying a hypoeutectic Al-Si alloy under conditions of different cooling rates. J. Alloys Compd. 2019, 806, 909-916. [CrossRef]

12. Li, L.; Li, D.; Mao, F.; Feng, J.; Kang, Y. Effect of cooling rate on eutectic Si in Al-7.0Si-0.3Mg alloys modified by La additions. J. Alloys Compd. 2020, 826, 154206. [CrossRef]

13. Lin, Y.C.; Luo, S.; Huang, J.; Yin, L.; Jiang, X. Effects of solution treatment on microstructures and micro-hardness of a Sr-modified Al-Si-Mg alloy. Mater. Sci. Eng. A 2018, 725, 530-540. [CrossRef]

14. Chen, R.; Xu, Q.; Jia, Z.; Liu, B. Precipitation behavior and hardening effects of Si-containing dispersoids in Al-7Si-Mg alloy during solution treatment. Mater. Des. 2016, 90, 1059-1068. [CrossRef]

15. Abdelaziz, M.H.; Samuel, A.M.; Doty, H.W.; Samuel, F.H. Effect of extended thermal exposure and alloying elements on the morphology of eutectic Si in Al-Si cast alloys. Int. J. Metalcast. 2020, 14, 1013-1024. [CrossRef] 
16. Lee, C.; Shin, K.; Kim, Y. Dependence of tensile ductility on damage evolution of eutectic Si-particles and pre-existing micro-voids in Al-Si casting alloy. Eng. Fract. Mech. 2017, 175, 339-356. [CrossRef]

17. Osorio, W.R.; Garcia, L.R.; Goulart, P.R.; Garcia, A. Effects of eutectic modification and T4 heat treatment on mechanical properties and corrosion resistance of an Al-9wt\%Si casting alloy. Mater. Chem. Phys. 2007, 106, 343-349. [CrossRef]

18. Mulazimoglu, M.H.; Drew, R.A.L.; Gruzileski, J.E. Solution treatment study of cast Al-Si alloys by electrical conductivity. Can Metall. Quart. 1989, 28, 251-258. [CrossRef]

19. Haghayeghi, R.; Timelli, G. An investigation on primary Si refinement by Sr and Sb additions in a hypereutectic Al-Si alloy. Mater. Lett. 2020, 283, 128779. [CrossRef]

20. Liu, X.; Zhang, P.; Xue, J.; Zhu, C.; Li, X.; Wang, Z. High energy efficiency of Al-based anodes for Al-air battery by simultaneous addition of Mn and Sb. Chem. Eng. J. 2020, 417, 128006. [CrossRef]

21. Zhu, P.Y.; Liu, Q.Y. Kinetics of granulation of discontinuous phase in eutectic structures. Metar. Sci. Tech-Lond. 1986, 2, 500-507. [CrossRef]

22. Wan, G.; Sahm, P.R. Particle growth by coalescence and Ostwald ripening in rheocasting of PbSn. Acta Metall. Mater. 1990, 38, 2367-2372. [CrossRef]

23. Mueller, M.G.; Fornabaio, M.; Mortensen, A. Silicon particle pinhole defects in aluminium-silicon alloys. J. Mater. Sci. 2017, 52, 858-868. [CrossRef]

24. Abdelaziz, M.H.; Samuel, A.M.; Doty, H.W.; Samuel, F.H. Effect of morphological changes of eutectic Si particles on the ambient and high temperature tensile properties of $\mathrm{Zr}$ containing Al-Si alloys. J. Mater. Res. Technol. 2020, 9, 5962-5981. [CrossRef]

25. Tong, Z.; Li, S.; Ruan, X.; Bao, H. A comprehensive first-principles analysis of phonon thermal conductivity and electron-phonon coupling in different metals. Phys. Rev. B 2019, 100, 144306. [CrossRef]

26. Wang, Z.; Wang, H.; Yang, M.; Sun, W.; Yin, G.; Zhang, Q.; Ren, Z. Thermal reliability of Al-Si eutectic alloy for thermal energy storage. Mater. Res. Bull. 2017, 95, 300-306. [CrossRef]

27. Sauvage, X.; Bobruk, E.V.; Murashkin, M.Y.; Nasedkina, Y.; Enikeev, N.A.; Valiev, R.Z. Optimization of electrical conductivity and strength combination by structure design at the nanoscale in Al-Mg-Si alloys. Acta Mater. 2015, 98, 355-366. [CrossRef]

28. Jiang, H.; Li, S.; Zhang, L.; He, J.; Zheng, Q.; Song, Y.; Li, Y.; Zhao, J. The influence of rare earth element lanthanum on the microstructures and properties of as-cast 8176 (Al-0.5Fe) aluminum alloy. J. Alloys Compd. 2021, 859, 157804. [CrossRef]

29. Costa, T.A.; Dias, M.; Gomes, L.G.; Rocha, O.L.; Garcia, A. Effect of solution time in T6 heat treatment on microstructure and hardness of a directionally solidified Al-Si-Cu alloy. J. Alloys Compd. 2016, 683, 485-494. [CrossRef]

30. Miyajima, Y.; Komatsu, S.Y.; Mitsuhara, M.; Hata, S.; Nakashima, H.; Tsuji, N. Change in electrical resistivity of commercial purity aluminium severely plastic deformed. Phil. Mag. 2010, 90, 4475-4488. [CrossRef]

31. Evans, H.E. Stress effects in high temperature oxidation of metals. Int. Mater. Rev. 1995, 40, 1-40. [CrossRef]

32. Caceres, C.H. A phenomenological approach to the quality index of Al-Si-Mg casting alloys. Int. J. Cast Metal. Res. 2000, 12, 367-375. [CrossRef]

33. Ragab, K.A.; Bouazara, M.; Chen, X.G. Quality index charts of Al-Si-Mg semi solid alloys subjected to multiple temperatures aging treatments and different quenching media. Materials 2019, 12, 1834. [CrossRef] [PubMed]

34. Kelly, A.; Tyson, W.R. Tensile properties of fibre-reinforced metals: Copper/tungsten and copper/molybdenum. J. Mech. Phys. Solids 1965, 13, 329-338. [CrossRef]

35. Yang, J.; Cady, C.; Hu, M.S.; Zok, F.; Mehrabian, R.; Evans, A.G. Effects of damage on the flow strength and ductility of a ductile $\mathrm{Al}$ alloy reinforced with $\mathrm{SiC}$ particulates. Acta Metall. Mater. 1990, 38, 2613-2619. [CrossRef]

36. Wang, H.Y.; Liu, F.; Chen, L.; Zha, M.; Liu, G.J.; Jiang, Q.C. The effect of Sb addition on microstructures and tensile properties of extruded Al-20Mg $\mathrm{MSi}_{2}-4 \mathrm{Cu}$ alloy. Mater. Sci. Eng. A 2016, 657, 331-338. [CrossRef]

37. Tong, X.; Ghosh, A. Fabrication of in situ TiC reinforced aluminum matrix composites. J. Mater. Sci. 2001, 36, 4059-4069. [CrossRef] 